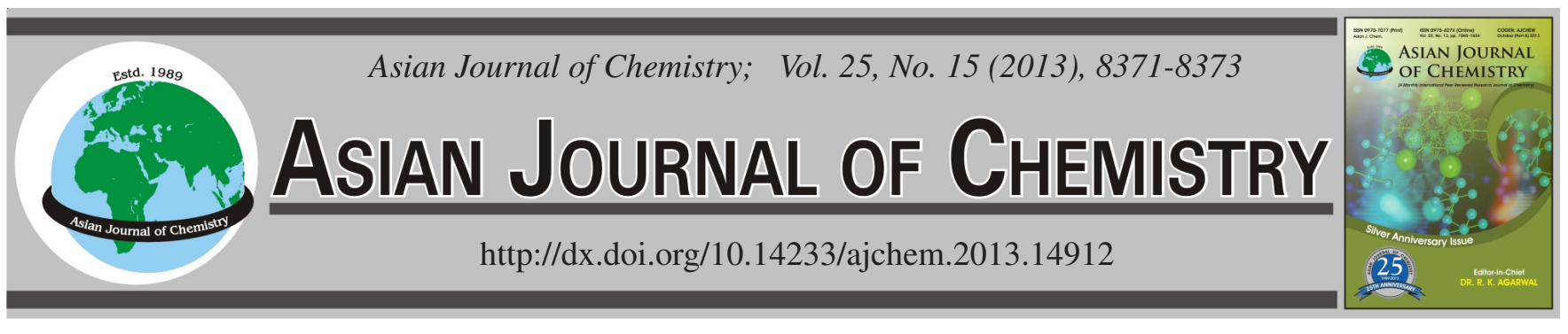

\title{
Antimicrobial and Antiinflammatory Activity of the Hydrogels Containing Rutin Delivery
}

\author{
Himesh Soni ${ }^{1, *}$, Jitender Malik ${ }^{2}$, A.K. Singhai ${ }^{2}$ and SARVESh Sharma ${ }^{2}$
}

${ }^{1}$ Suresh Gyan Vihar University, Jaipur-302 025, India

${ }^{2}$ Lakshmi Narain College of Pharmacy, Raisen Road, Bhopal-462 021, India

*Corresponding author: E-mail: himeshsoni@ rediffmail.com

(Received: 31 October 2012;

Accepted: 21 August 2013)

AJC-13953

Flavonoids are principal active constituents have been used to treatment of various human diseases. Rutin (quercetin-3-rhamnosyl glucoside)
as the flavonoids display anticancer, antiviral, antiinflammatory and heart disease protective activities. Rutin by acting as antioxidants
exhibited several beneficial effects, such as antiinflammatory, antiallergic, antiviral as well as an anticancer activity. The objective of
present study was to formulate hydrogels containing rutin at various concentrations i.e., $0.020,0.025$ and $0.030 \%$ (w/w). Hydrogels were
prepared using Carbopol 934 and a methanolic (co-solvent) dispersion of rutin. The hydrogels were subjected to antimicrobial and
antiinflammatory activity. The zone of inhibition of rutin in hydrogel systems was evaluated by cup plate method against bacteria $i . e .$,
Staphylococcus aureus, Staphylococcus glurance and Eschericia coli. The antiinflammatory activity of the hydrogel systems was also
carried out by Carrageenan-induced rat paw edema model. Results of in vivo activity led to the conclusion that the hydrogel H2 formulation
showed predominantly significant activity, which is comparable to the standard drug.
Key Words: Rutin, Staphylococcus aureus, Staphylococcus glurance, Eschericia coli and hydrogel.

\section{INTRODUCTION}

The hydrogel can be defined as a cross-linked polymeric network which has the capacity to hold water within its porous structure. The water holding capacity of the hydrogels arise mainly due to the presence of hydrophilic groups, viz. amino, carboxyl and hydroxyl groups, in the polymer chains ${ }^{1}$. The hydrogel is a permanent or chemical gel stabilized by covalently cross-linked networks. These chemical hydrogels may be prepared either by cross linking water-soluble polymers or by converting hydrophobic polymers into hydrophilic polymers that are then cross-linked to form a network. With such a structure, hydrogels are able to swell, absorbing a large amount of water without the polymer dissolving, which gives them characteristics similar to those of soft tissue ${ }^{2}$. Therefore, hydrophilic gels called hydrogels are cross-linked materials absorbing large quantities of water without dissolving. Softness, smartness and the capacity to store water make hydrogels unique materials ${ }^{3}$. Hydrogels can be designed to change properties (e.g. swelling/collapse or solution-to-gel transitions) in response to externally applied triggers, such as temperature, ionic strength, solvent polarity, electric/magnetic field, light, or small (bio) molecules ${ }^{4}$. Rutin is a flavonoid present in the plant kingdom as allelopathic substances. Rutin (Fig. 1) is the rhamnoglucoside of the flavonoid quercetin and found in many plants and used for treatment of various diseases related to the vascular $^{5}$. It is quercetin-3-rutinoside or 3,3',4', 5,7-pentahydroxy flavones-3-rutinoside and has a chemical formula $\mathrm{C}_{27} \mathrm{H}_{30} \mathrm{O}_{16}$.

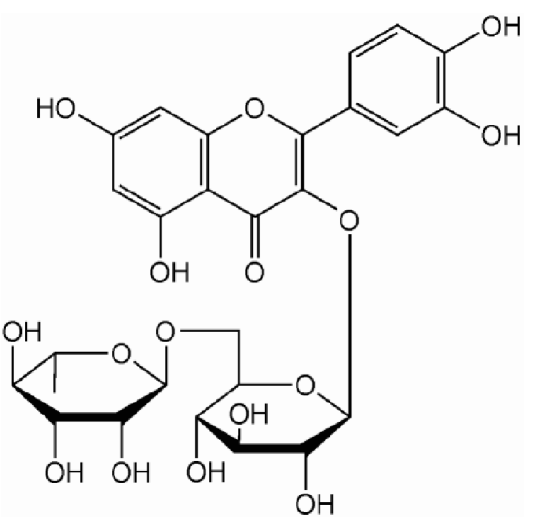

Fig. 1. Structure of rutin

It has been reported that phenolic compounds show antimicrobial activity against a wide range of microorganisms ${ }^{6}$. They also possess significant antiinflammatory activity by virtue of the presence of the free phenolic groups. We already reported the formulation and characterization of the hydrogels containing rutin. An acute toxicity study in rabbits was reported by Lima et $a .^{7}$ showing the innocuity of rutin after 
daily oral doses of $0.01 \mathrm{~mol} \mathrm{~kg}^{-1}$, through the evaluation of blood markers of toxicity. Furthermore, a critical review published in 2007 concluded that quercetin, the aglicone of rutin, does not produce adverse health effect taking into account an estimated level of dietary intake ${ }^{8}$. Recently, it has been demonstrated that rutin does not have genotoxic effects on HCT cells ${ }^{9}$. Taking all these aspects, the objective of this study was to develop a hydrogels containing rutin in varying concentration and to investigate the antiinflammatory and antimicrobial potential.

\section{EXPERIMENTAL}

Rutin was isolated from Annona squamosa leaves. It is identified and characterized by various analytical techniques like HPLC, FT-IR. Carbopol 934 and HPMC were purchased from Hi-media laboratories Pvt. Ltd. All the other chemicals and reagents used were of analytical grade.

Nutrient broth (NB), Nutrient agar (NA), Muller-Hinton agar, Peptone water and antibiotics gentamycin were procured from Hi-media laboratories, Mumbai, India.

Test organisms: The test organisms Staphylococcus aureus (MTCC 265), Staphylococcus glurance (MTCC 265), Eschericia coli (MTCC 167), were procured from Microbial Tissue Culture technology Centre, lab. Chandigarh, India.

Preparation of hydrogel systems: In separate container, the hydrogel forming polymers were dissolved in small amount of double distilled water in various proportions as shown in Table-1 and then remaining ingredients i.e., glycerine and sodium benzoate were added. Now, methanolic dispersion of rutin $(1 \mathrm{mg} / \mathrm{mL})$ was added to it and make up the volume up to $100 \mathrm{~mL}$. Then, sonicated (Lark probe sonicator) at $6 \varphi$ frequency, $20 \mathrm{~s}$ at $28^{\circ} \mathrm{C}$. The above formulation was allowed to stand for $24 \mathrm{~h}$ at room temperature. The $\mathrm{pH}$ of this gel preparation was maintained $6 \pm 0.4$ and stored in well closed container.

\section{TABLE-1}

COMPOSITION OF HYDROGEL FORMULATIONS

\begin{tabular}{lccc}
\hline \multirow{2}{*}{ Components } & \multicolumn{3}{c}{ Quantity } \\
\cline { 2 - 4 } & H1 $0.020 \%$ & H2 $0.025 \%$ & H3 $0.030 \%$ \\
$(w / w)$ & $(w / w)$ & $500 \mathrm{mg}$ \\
\hline Carbopol 934 & $500 \mathrm{mg}$ & $500 \mathrm{mg}$ & $500 \mathrm{mg}$ \\
HPMC & $500 \mathrm{mg}$ & $500 \mathrm{mg}$ & $500 \mathrm{mg}$ \\
Acaica & $500 \mathrm{mg}$ & $500 \mathrm{mg}$ & $2 \mathrm{~mL}$ \\
Glycerine & $2 \mathrm{~mL}$ & $2 \mathrm{~mL}$ & $100 \mathrm{mg}$ \\
Sodium benzoate & $100 \mathrm{mg}$ & $100 \mathrm{mg}$ & $4.8 \mathrm{mg}$ \\
Rutin & $3.2 \mathrm{mg}$ & $4 \mathrm{mg}$ & \\
\hline
\end{tabular}

\section{Antimicrobial activity by disc diffusion nethod}

Preparation of inoculum: E.coli, S. glurance and S.aureus strains were used. $50 \mathrm{~mL}$ of nutrient broth was prepared in $100 \mathrm{~mL}$ conical flask. It was sterilized and then inoculated with inoculum with the help of sterile loop in laminar air flow from preserved slants ${ }^{10}$. They were then kept in incubator at $37^{\circ} \mathrm{C}$ for sufficient period of time for organism to grow.

Preparation of media: $200 \mathrm{~mL}$ of nutrient agar media was prepared and the $\mathrm{pH}$ was maintained at 7.0-7.2.
Pour plate techenique: $1 \mathrm{~mL}$ of prepared inoculums was poured in sterile Petri dish and then poured $15 \mathrm{~mL}$ of nutrient agar media in it and allowed to solidify.

Disc diffusion method: After solidification the disc of whatman filter paper imbibed with $20 \mu \mathrm{L}$ of sample was carefully placed with the help of forceps at the center of the Petri dish of different doses and then kept in incubator for $24 \mathrm{~h}^{11}$.

Standard: Gentamycin $(50 \mu \mathrm{g} / \mathrm{disc})$, was taken as the positive control.

Measurment of zones: The zone of inhibition was measured with the help of zone reader.

Antiinflammatory activity: Animals were divided into six groups with three animals in each; the first three groups served as controls: (a) un-inflamed, injected with saline; (b) inflamed, injected with carrageenan; (c) inflamed, treated with the reference product (oleogel diclofenac sodium). The other three groups were inflamed and treated with the hydrogel systems H1, H2 and H3.Carrageenan solution (1\% w/v, in normal saline) was used to induce inflammation. The animals were placed singly in observation chambers for $10 \mathrm{~min}$ to minimize any stress-related behavioural changes. The mice then received sub-plantar administration of $50 \mu \mathrm{L}$ of the carrageenan solution in the left hind paw and were returned immediately to the observation chamber. The thickness ( $\mathrm{mm}$ ) of the paw was measured at $0,1,2,3$ and $4 \mathrm{~h}$ after carrageenan administration, using an electronic digital Vernier caliper ${ }^{12}$. The hydrogel formulations and the standard were applied to the plantar surface of the left hind paw by gently rubbing $0.5 \mathrm{~g}$ of the formulation 50 times with the index finger. After $0.5 \mathrm{~h}$, pleurisy was induced by injecting $50 \mu \mathrm{L}$ of $1 \% \mathrm{w} / \mathrm{v}$ carrageenan solution subcutaneously into the sub-plantar surface of the left paw of the mice. Control un-inflamed animals received $50 \mu \mathrm{L}$ normal saline subcutaneously into the sub-plantar surface of the left paw.

$$
\text { Inhibition of edema }(\%)=\left(1-\frac{V_{t}}{V_{c}}\right) \times 100
$$

where, $\mathrm{V}_{\mathrm{t}}=$ volume of edema in test, $\mathrm{V}_{\mathrm{c}}=$ volume of edema in control.

\section{RESULTS AND DISCUSSION}

The formulated hydrogels of different concentration of rutin were evaluated for antimicrobial and antiinflammatory activity. Different composition of hydrogel were tabulated in Table-1. The zone of inhibition for three different strain of bacteria i.e., S. aureus, S. glurence and E. coli for $\mathrm{H} 2$ formulation was found to be 3,9 and $5 \mathrm{~cm}$, respectively (Table-2 and Fig. 2). Our other two $\mathrm{H} 1$ and $\mathrm{H} 3$ formulation also show moderate inhibition for bacterial strain. The zone of inhibition of $\mathrm{H} 2$ formulation signifies that minimum concentration available of drug is sufficient to prevent the growth of microbe. Antimicrobial of plant origin is effective in the treatment of several infections and important for the antimicrobial activity. The action of compounds containing phenolic (flavonoid) groups may be related to inhibition of hydrolytic enzyme or other interactions to inactivate microbial adhesions, on specific transport of carbohydrates etc. Phenolic compounds exhibit a wide range of antiallergenic, antiinflammatory, antimicrobial, 


\begin{tabular}{|c|c|c|c|c|c|}
\hline \multicolumn{6}{|c|}{$\begin{array}{c}\text { TABLE- } 2 \\
\text { ANTIMICROBIAL EFFECT OF HYDROGEL } \\
\text { SYSTEMS DRUGS BY CUP PLATE METHOD }\end{array}$} \\
\hline \multirow{3}{*}{ Bacterial strains } & \multicolumn{5}{|c|}{ Zone of inhibition (diameter in $\mathrm{mm}$ ) } \\
\hline & \multirow{2}{*}{ Ctl. } & \multirow{2}{*}{ Std. } & \multicolumn{3}{|c|}{ Formulation } \\
\hline & & & H1 & $\mathrm{H} 2$ & $\mathrm{H} 3$ \\
\hline E. coli & - & 22 & 01 & 05 & 07 \\
\hline S. aureus & - & 30 & Nil & 03 & 06 \\
\hline S. glurence & - & 17 & Nil & 09 & 12 \\
\hline
\end{tabular}

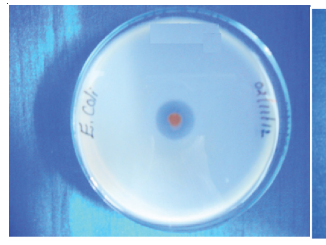

Standard for E.coil

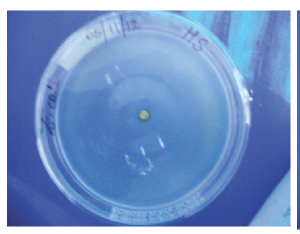

$\mathrm{H} 2$ for E.coli

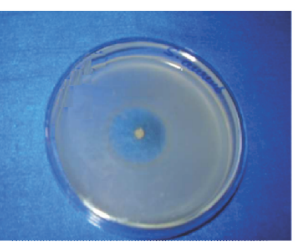

Standard for S.aureus

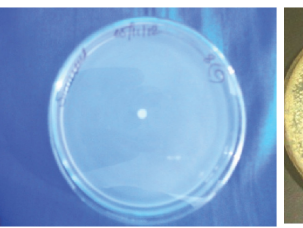

H2 for S.aureus

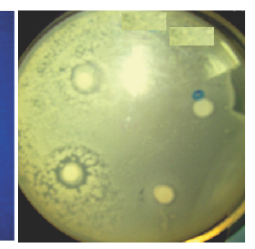

Standard for S. glurance

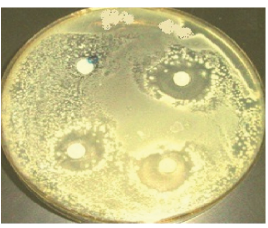

H2 for S.glurance
Fig. 2. Observation of zone of inhibition of $\mathrm{H} 2$ formulation

antioxidant, antithrombotic, cardio protective and vasodilator effects. Rutin has shown significant anti microbial activity against both the gram positive and gram negative bacteria. The antiinflammatory activity of different hydrogel formulation was carried out with the standard Oleogel. The formulated hydrogels $\mathrm{H} 2$ decreased the paw oedema volume by $26.07 \%$ within $4 \mathrm{~h}$ after administration, while standard drug decreased the paw edema volume by $41.44 \%$ (Table-3, Fig. 3) when compared with the paw edema volume of the control.

\begin{tabular}{ccccc}
\multicolumn{5}{c}{ TABLE-3 } \\
\multicolumn{5}{c}{ ANTIINFLAMMATORY EFFECT IN } \\
& TERM OF \% INHIBITION OF EDEMA \\
\hline Time $(\mathrm{h})$ & H1 & H2 & H3 & Oleogel (standard) \\
\hline 1 & 68.67 & 71.78 & 72.04 & 80.11 \\
2 & 69.05 & 72.35 & 73.97 & 87.54 \\
3 & 34.87 & 37.49 & 39.01 & 48.37 \\
4 & 24.56 & 26.07 & 29.63 & 41.44 \\
5 & 17.91 & 19.96 & 21.04 & 28.34 \\
\hline
\end{tabular}

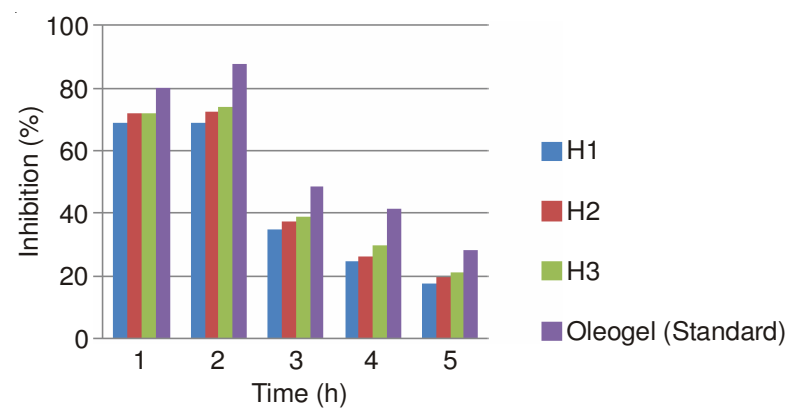

Fig. 3. Average $\%$ edema inhibition by different hydrogel formulation

\section{Conclusion}

Flavonoid is major phenolic compounds are becoming the major subject of medical research. They have been reported to possess many useful properties, including oestrogenic activity, antiinûammatory activity, enzyme inhibition, antimicrobial activity. For centuries, preparations that contain flavonoids as the principal physiologically active constituents have been used by physicians and lay healers in attempts to treat human diseases ${ }^{13,14}$. Hydrogels have been used to deliver active component. Instead of conventional creams, the hydrogels have been formulated for better patient compliance. These hydrogels have moisturizing properties therefore scaling and dryness is not expected with this drug delivery system ${ }^{15}$. Many antifungal formulations have been developed as hydrogel formulation. It has shown better absorption than conventional cream formulations ${ }^{16}$. The present study revealed that the hydrogel $\mathrm{H} 2$ formulation showed predominantly significant activity, which is comparable to $\mathrm{H} 1$ and $\mathrm{H} 3$. Since $\mathrm{H} 2$ contained $0.025 \% \mathrm{w} / \mathrm{w}$ amount of rutin which evoked antimicrobial and antiinflammatory activity more or less similar to $\mathrm{H} 3$ formulation which contained $0.030 \% \mathrm{w} / \mathrm{w}$ amount of rutin.

\section{REFERENCES}

1. Y. Tanaka, J.P. Gong and Y. Osada, Progr. Polym. Sci., 30, 1 (2005).

2. I. Gibas and H. Janik. Chem. Chem. Technol., 4, 297 (2010).

3. K. Haraguchi and T. Takehisa, Adv. Mater., 14, 1120 (2002).

4. R.V. Ulijn, N. Bibi, V. Jayawarna, P.D. Thornton, S.J. Todd, R.J. Mart, A.M. Smith and J.E. Gough, Mater. Today, 10, 40 (2007).

5. G. Toker, S. Turkoz and N. Erdemogly, J. Chem. Soc. Pak, 20, 240 (1998).

6. A. Aberoumand and S.S. Deokule, Pak. J. Nutr., 7, 582 (2008).

7. L. Lima, T.T. Oliveira, T.J. Nagem, A.S. Pinto, E.Q. Lima and J.F. Silva, Acta Farm. Bonaerense, 22, 21 (2003).

8. M. Harwood, B. Danielewska-Nikiel, J.F. Borzelleca, G.W. Flamm, G.M. Williams and T.C. Lines, Food Chem. Toxicol., 45, 2179 (2007).

9. J.C. Marcarini, R.C. Luiz, L.R. Ribeiro, C.B. Ho\$mann-Campo and M.S. Mantovani, Exp. Toxicol. Pathol., 63, 450 (2011).

10. A. Basile, S. Giordano, J.A. Lopez-Saez and R.C. Cobianchi, Phytochemistry, 52, 79 (1999).

11. C.A. Winter, E.A. Risley and G.W. Nuss, Proc. Soc. Exp. Biol. Med., 111, 544 (1962).

12. A.A. Mohammed, A.A. Khalil and H.E.S. El-Beltagi, Grasas y Aceites, 61, 67 (2010).

13. B. Havsteen, Flavonoids, Biochem. Pharmacol., 32, 1141 (1983).

14. J.B. Harborne and H. Baxter, The Handbook of Natural Flavonoids, John Wiley \& Sons, Chichester, UK, Vol, 2, pp. 413-15 (1999).

15. N. Trookman, R. Rizer, T.J. Stephens and R. Trancik, J. Am. Acad. Dermatol., 75, 730 (2007).

16. J.Y. Chang, Y.K. Oh, H.S. Kong, E.U. Kim, D.D. Jang and K.T. Nam, J. Control. Rel., 82, 39 (2002). 